\title{
The effect of diluting diets with ground and pelleted or with whole wheat on the performance of growing turkeys*
}

\author{
J. Jankowski ${ }^{1}$, D. Mikulski ${ }^{1,3}$, Z. Zduńczyk ${ }^{2}$, M. Mikulska ${ }^{1}$ \\ and J. Juśkiewicz ${ }^{2}$ \\ ${ }^{1}$ University of Warmia and Mazury, Department of Poultry Science \\ Oczapowskiego 5, 10-718 Olsztyn, Poland \\ ${ }^{2}$ Institute of Animal Reproduction and Food Research, Polish Academy of Sciences \\ Tuwima 10, 10-747 Olsztyn, Poland
}

(Received 5 March 2012; revised version 1 October 2012; accepted 10 December 2012)

\begin{abstract}
The objective of this study was to determine the effect of moderate dilution (gradually up to $22.5 \%$ ) of standard diets (C) with wheat in different physical forms, ground and pelleted (GW) or whole (WW), on growth rate, feed conversion ratio (FCR), carcass yield, and incidence of footpad dermatitis (FPD) in growing heavy-type turkeys. Dietary treatments in which part of the basal diet (control, C) was replaced with a low, medium, or high wheat content $(8.2 \%, 13.3 \%$, or $18.2 \%$ on average in groups $\mathrm{W}_{\mathrm{L}}, \mathrm{W}_{\mathrm{M}}$, and $\mathrm{W}_{\mathrm{H}}$, respectively) were compared. Seven experimental groups consisted of six replicates each ( $\mathrm{n}=30$ birds) fed from 4 to 18 weeks of age. After four weeks of experimental feeding, groups $\mathrm{GW}_{\mathrm{L}}$ and $\mathrm{WW}_{\mathrm{L}}$, relative to group $\mathrm{C}$, were characterized by higher coefficients of dry matter digestibility $(\mathrm{P}=0.003)$, apparent nitrogen retention $(\mathrm{P}=0.096)$, and energy metabolizability $(\mathrm{P}=0.003)$, as well as by a higher metabolizable energy content of the daily ration $(\mathrm{P}<0.001)$. The beneficial influence of wheat, both ground and whole, was lower at higher levels of dietary dilution. In 8-week-old turkeys, the symptoms of FPD were significantly less severe in groups $\mathrm{GW}_{\mathrm{L}}$ and $\mathrm{WW}_{\mathrm{L}}(\mathrm{P}=0.039)$. In birds aged 18 weeks, no significant differences were found among groups. Neither the amount of wheat nor its physical form had a significant effect on the average body weight of growing turkeys. Throughout the experiment, only in groups $\mathrm{WW}_{\mathrm{M}}$ and $\mathrm{WW}_{\mathrm{H}}$ were FCR values lower than in group $\mathrm{C}(\mathrm{P}<0.001)$. An increase in the wheat content of diets led to a linear decrease in FCR $(\mathrm{P}<0.001)$, and average FCR values were significantly $(\mathrm{P}=0.004)$ lower in WW than in GW groups. Whole wheat, compared with ground pelleted wheat, contributed to an increase in gizzard weight $(\mathrm{P}=0.003)$, although it had no influence on the proportions of breast muscles, leg muscles, and fat in turkey carcasses.
\end{abstract}

\footnotetext{
* Supported by the Polish Committee for Scientific Research, Project No. NN 311400339

${ }^{3}$ Corresponding author: e-mail: dariusz.mikulski@uwm.edu.pl
} 
KEY WORDS: wheat, diet dilution, growth performance, nutrient utilization, carcass quality, turkey

\section{INTRODUCTION}

Recent years have witnessed the growing popularity of feeding whole grain to poultry. This tendency results from economic reasons, the beneficial influence of whole grain on the development and health of the digestive tract of birds, and greater consumer acceptance of a more 'natural' feeding system (Gabriel et al., 2008). Originally, the purpose of such treatment was to reduce the transport and processing components of feed costs (Majewska, 1996; Bennett et al., 2002b). Studies have also shown that this mode of feeding improves the growth performance of birds and feed efficiency (Ravindran et al., 2006), most probably due to better development of the gastrointestinal tract of broilers and an increase in relative gizzard weight (Amerah et al., 2007). A large and more active gizzard can improve starch digestibility by serving as a mixing compartment for digestive juices and nutrients (Hetland et al., 2002). The results of recent studies (Amerah and Ravindran, 2008; Biggs and Parson, 2009) justify the expectation that feeding whole grain will improve not only the function of the gizzard, but also the health of birds. A number of studies, extensively reviewed by Svihus (2011), have shown improvements in nutrient utilization and bird performance as a result of including whole grains or coarse feed and fibre particles in diets for broiler chickens.

In contrast to numerous experiments on chickens, studies investigating the effects of whole grain in growing turkeys remain scarce, and their results are inconclusive. Without dilution, turkeys have been successfully fed diets containing up to $50 \%$ whole wheat or barley (Bennett et al., 2002b). At the highest level of dilution, where whole wheat dilution was $50 \%$ of the diet, body weight and the weight of breast meat per bird were reduced by $15 \%$ and $20 \%$, respectively (Bennett and Classen, 2003). Such results, reported for turkeys with final body weight below $14 \mathrm{~kg}$, suggest that the degree of diet dilution with whole wheat should be decreased, particularly in heavy-type birds.

The objective of this study was to determine the effect of moderate dilution of standard diets with wheat in different physical forms (ground and pelleted or whole) on growth rate, feed conversion ratio, carcass yield and incidence of footpad dermatitis in growing heavy-type turkeys. 


\section{MATERIAL AND METHODS}

\section{Birds and housing}

The experiment was carried out at the Research Laboratory of the Department of Poultry Science, University of Warmia and Mazury in Olsztyn, according to the guidelines of the Local Animal Experimentation Ethics Committee. A total of 1260 four-week-old heavy-type BIG-6 turkey males were kept in pens (30 turkeys per pen, $10 \mathrm{~m}^{2}$ ) on litter in a building with a controlled environment. The temperature and lighting programmes were consistent with the recommendations of Aviagen Inc. (2007). The birds had free access to feed and water. The trial was conducted to 18 weeks of age.

\section{Diets}

The four-phase feeding programme applied in the study followed commercial recommendations. Pelleted control diets (group C), whose composition is given in Table 1 and whose nutritive value was consistent with British United Turkeys recommendations (BUT, 2005), were used in each of the four successive feeding periods (three 4-week periods and the final 2-week period). In experimental groups, part of the basal diet (low, medium and high, respectively) was replaced with ground pelleted $\left(\mathrm{GW}_{\mathrm{L}}, \mathrm{GW}_{\mathrm{M}}, \mathrm{GW}_{\mathrm{H}}\right)$ or whole $\left(\mathrm{WW}_{\mathrm{L}}, \mathrm{WW}_{\mathrm{M}}, \mathrm{WW}_{\mathrm{H}}\right)$ wheat grain, according to the experimental design (Table 2). Experimental groups consisted of six replicates, 30 birds each.

\section{Growth trial}

At the end of each period, in week $8,12,16$, and 18 of the experiment, the birds were weighed and feed intake was recorded. The feed conversion ratio was calculated for each period. At 8 weeks of age and at the termination of the experiment, the excreta dry matter (DM) was analysed and foot-pad dermatitis (FPD) scores were determined according to the method described by Hocking et al. (2008).

\section{Balance trial}

After 4 weeks of feeding, 14 birds were randomly selected from each treatment (7 replications, 2 birds each) and transferred to battery cages for balance trials. Cages were thermostatically controlled, and turkeys had free access to water from nipple drinkers. The birds received the experimental diets ad libitum. 
All diets contained $\mathrm{TiO}_{2}$ at a rate of $5 \mathrm{~g} / \mathrm{kg}$ as an indigestible dietary marker for the calculation of nutrient digestibility coefficients. After a two-day preliminary period, a collection period was continued for 5 days; the excreta were collected daily, freeze-dried and ground through a $0.5 \mathrm{~mm}$ screen.

Table 1. Composition (g/kg as-fed basis) and calculated nutrient content of control diets fed to turkeys at a different age

\begin{tabular}{|c|c|c|c|c|}
\hline \multirow{2}{*}{ Indices } & \multicolumn{4}{|c|}{ Feeding period, weeks } \\
\hline & 5 to 8 & 9 to 12 & 13 to 16 & 17 to 18 \\
\hline \multicolumn{5}{|l|}{ Ingredient } \\
\hline wheat & 222.6 & 279.9 & 613.9 & 707.0 \\
\hline maize & 200.0 & 200.0 & - & - \\
\hline potato protein & 30.0 & - & - & - \\
\hline sunflower meal & 50.0 & 50.0 & 50.0 & 50.0 \\
\hline soyabean meal ( $46 \%$ of CP) & 337.7 & 317.9 & 196.4 & 116.1 \\
\hline rape seed & 50.0 & 50.0 & 50.0 & 50.0 \\
\hline soyabean oil & 57.3 & 55.4 & 46.0 & 34.8 \\
\hline limestone & 17.3 & 16.6 & 17.4 & 17.1 \\
\hline monocalcium phosphate & 16.1 & 14.9 & 12.2 & 11.3 \\
\hline choline chloride & 0.8 & 0.8 & 0.8 & 0.8 \\
\hline $\mathrm{NaCl}$ & 2.2 & 2.2 & 2.4 & 2.4 \\
\hline $\mathrm{NaHCO}_{3}$ & 1.5 & 1.5 & 1.5 & 1.5 \\
\hline DL-methionine (99) & 3.9 & 3.2 & 2.5 & 2.2 \\
\hline L-lysine (99) & 5.1 & 3.7 & 3.6 & 3.7 \\
\hline L-threonine (99) & 1.3 & 1.4 & 0.8 & 0.6 \\
\hline L-arginine (98.5) & 1.7 & - & - & - \\
\hline vitamin-mineral premix & $2.5^{1}$ & $2.5^{2}$ & $2.5^{2}$ & $2.5^{2}$ \\
\hline \multicolumn{5}{|l|}{ Calculated } \\
\hline $\mathrm{ME}, \mathrm{kcal} / \mathrm{kg}$ & 3059 & 3059 & 3059 & 3059 \\
\hline crude protein & 255.0 & 229.0 & 196.0 & 170.0 \\
\hline Lys & 17.2 & 14.1 & 11.4 & 9.6 \\
\hline Met + Cys & 12.0 & 10.6 & 9.10 & 8.2 \\
\hline $\mathrm{Ca}$ & 11.0 & 10.5 & 10.0 & 9.5 \\
\hline available $\mathrm{P}$ & 5.0 & 4.8 & 4.5 & 4.3 \\
\hline $\mathrm{Na}$ & 1.5 & 1.5 & 1.5 & 1.5 \\
\hline
\end{tabular}

${ }^{1}$ supplied the following per $\mathrm{kg}$ of starter diet (5-8 week): IU: vit. A (all trans-retinol acetate) 15000 , vit. $\mathrm{D}_{3}$ (cholecalciferol) 4000 ; mg: vit. $\mathrm{E}$ (dl- $\alpha$-tocopheryl acetate) 40 , vit. $\mathrm{K}_{3} 2.5$, vit. $\mathrm{B}_{1}$ 2.5 , vit $\mathrm{B}_{2} 10$, vit. $\mathrm{B}_{6} 5$, niacin 70 , pantothenic acid 20 , folic acid 2, biotin 0.3 , choline 600 , Mn 120, Zn 90, Fe 60, Cu 10, I 1, Se 0.3, Diclazuril 1; ${ }^{2}$ supplied the following per kg of grower and finisher diet (9-18 week): IU: vit. A 13 000, vit. $\mathrm{D}_{3} 3$ 000; mg: vit. E 35, vit. $\mathrm{K}_{3} 2$, vit. $\mathrm{B}_{1}$ 2, vit. $\mathrm{B}_{2} 8$, vit $\mathrm{B}_{6} 3.5$, niacin 65 , pantothenic acid 18 , folic acid 1.5 , biotin 0.2 , choline 400 , Mn 100 , $\mathrm{Zn}$ 80, Fe 50, Cu 8, I 0.8, Se 0.3

\section{Sample collection}

Eight birds representing the average body weight of the control group and groups with the lowest and highest addition of wheat (40 birds in total) were sacrificed by cervical dislocation. The carcasses were scalded, defeathered, and eviscerated. Following evisceration, whole carcasses were air pre-chilled at $12^{\circ} \mathrm{C}$ 
for $30 \mathrm{~min}$, air chilled and stored at $4{ }^{\circ} \mathrm{C}$, and then hand-deboned on a cone $24 \mathrm{~h}$ post-mortem. Abdominal fat, giblets, breast meat (including M. pectoralis major and M. pectoralis minor), and leg meat (including thigh and drumstick) were weighed. The weights of the muscles, giblets and fat were determined relative to live body weight.

Table 2. Experimental design

\begin{tabular}{|c|c|c|c|c|}
\hline \multirow{2}{*}{ Indices } & \multicolumn{4}{|c|}{ Experimental groups $^{1}$} \\
\hline & $\mathrm{C}$ & $\mathrm{W}_{\mathrm{L}}$ & $\mathrm{W}_{\mathrm{M}}$ & $\mathrm{W}_{\mathrm{H}}$ \\
\hline \multicolumn{5}{|c|}{$\begin{array}{l}\text { Amount of wheat added, \% } \\
\text { weeks }\end{array}$} \\
\hline $5-8$ & 0 & 5 & 10 & 15 \\
\hline $9-12$ & 0 & 7.5 & 12.5 & 17.5 \\
\hline $13-16$ & 0 & 10 & 15 & 20 \\
\hline $17-18$ & 0 & 12.5 & 17.5 & 22.5 \\
\hline \multicolumn{5}{|c|}{$\begin{array}{l}\text { Predicted crude protein content, } \% \\
\text { weeks }\end{array}$} \\
\hline $5-8$ & 25.5 & 24.8 & 24.1 & 23.5 \\
\hline $9-12$ & 22.9 & 22.1 & 21.5 & 21.0 \\
\hline $13-16$ & 19.6 & 18.8 & 18.4 & 18.0 \\
\hline $17-18$ & 17.0 & 16.4 & 16.1 & 15.8 \\
\hline
\end{tabular}

Analysis

Samples of feed and dried excreta were analysed in triplicate for dry matter and nitrogen (AOAC, 2005). Ti was determined by inductively coupled plasma-optical emission spectrometry with excitation (ICP-OES) using the Ultima 2 sequence camera with vertical plasma by Horiba Jobin Yvon (procedure developed in the GBC Poland, Niezdrowice Laboratory). The gross energy value (GE) of feed and excreta was determined with the use of a Parr adiabatic oxygen bomb calorimeter (KL-10, Precyzja, Bydgoszcz, Poland).

\section{Statistical analysis}

For performance parameters and FPD scores, a pen was considered a replicate experimental unit for the statistical analysis. Other results were analysed with each turkey as a replicate. The model assumptions of normality and homogeneity of variance were examined by the Shapiro-Wilk and Levene tests, respectively. The percentage data (e.g., excreta DM content, digestibility coefficients and carcass traits) were transformed to arcsine of the square root before analysis to achieve homogeneity of variance. Because no statistical differences were observed between the transformed and original (untransformed) data, the statistics presented 
in this paper were calculated for the untransformed data. All data were subjected to one-way ANOVA according to the GLM procedure for Statistica 8.0 software (StatSoft Inc., 2007) according to the following model:

$$
\mathrm{Y}_{\mathrm{ij}}=\mu+\alpha_{\mathrm{i}}+\varepsilon_{\mathrm{ij}}
$$

where: $\mathrm{Y}_{\mathrm{ij}}$ - the observed dependent variable; $\mu$ - the overall mean of all the observations; $\alpha_{\mathrm{i}}$ - the mean effect of the $\mathrm{i}^{\text {th }}$ level of factor relative to $\mu$; $\varepsilon_{\mathrm{ij}}$ - the random error.

When a significant treatment effect was noted, the post-hoc two-sided Dunnett's test was used to determine differences between the control and each of the experimental groups. Differences between the forms of wheat (GW vs WW) were determined using the planned comparisons of trend analysis. In addition, linear and quadratic polynomial contrasts were used to evaluate the effect of different dietary levels of wheat, separately for each form of wheat, including the control group. Treatment effects were considered to be significant at $\mathrm{P} \leq 0.05$. All data were expressed as mean values with pooled SE.

\section{RESULTS}

Due to the similar energy value of the control diets (Table 1) and added wheat $(3070 \mathrm{kcal} / \mathrm{kg})$, the energy content in all of the experimental diets was comparable. In diets with low, medium, and high wheat inclusion, the average protein concentration decreased by $3.4 \%, 5.8 \%$, and $8 \%$, respectively, in comparison with the control diet.

The coefficients of dry matter digestibility, apparent nitrogen retention and energy metabolizability, as well as the metabolizable energy content of the dietary treatments, determined after four weeks, varied depending on the amount of wheat added to the basal diet, but were not affected by the physical form of the wheat (Table 3). Statistical analysis revealed that in groups of turkeys fed diets with an increasing wheat content, the values of the above coefficients, relative to the control group, were represented by a quadratic function, with the highest effects in the groups with a low addition of wheat. The coefficients of dry matter digestibility noted in groups $\mathrm{GW}_{\mathrm{L}}$ and $\mathrm{WW}_{\mathrm{L}}$ were significantly $(\mathrm{P}=0.003)$ higher than in the control group, whereas in the remaining groups ( $\mathrm{GW}$ and $\mathrm{WW}$ ), the influence of wheat inclusion levels was lower. The effects of ground wheat (groups GW) and whole wheat (groups WW) on dry mater digestibility were expressed as quadratic equations, significant at $\mathrm{P}<0.001$ and $\mathrm{P}=0.058$, respectively. The same dependencies were noted for apparent nitrogen retention (C vs GW, quadratic contrast, $\mathrm{P}=0.019$; $\mathrm{C}$ vs WW quadratic contrast, $\mathrm{P}=0.072$ ); energy metabolizability (C vs GW, quadratic contrast, $\mathrm{P}<0.001$; $\mathrm{C}$ vs $\mathrm{WW}$ quadratic contrast, $\mathrm{P}=0.052$ ), 
Table 3. Coefficients of dry matter and energy digestibility and apparent retention of nitrogen

\begin{tabular}{|c|c|c|c|c|}
\hline Indices & $\begin{array}{c}\text { DM } \\
\text { digestibility } \\
\%\end{array}$ & $\begin{array}{c}\mathrm{N} \text { retention } \\
\%\end{array}$ & $\begin{array}{c}\text { Energy } \\
\text { metabolizability } \\
\%\end{array}$ & $\begin{array}{c}\mathrm{ME} \\
\mathrm{MJ} / \mathrm{kg}\end{array}$ \\
\hline \multicolumn{5}{|l|}{ Groups } \\
\hline $\mathrm{C}$ & $61.2^{\mathrm{b}}$ & 44.6 & $68.6^{\mathrm{b}}$ & $12.28^{\mathrm{b}}$ \\
\hline GW & $70.8^{\mathrm{a}}$ & 59.4 & $76.6^{\mathrm{a}}$ & $14.03^{\mathrm{a}}$ \\
\hline $\mathrm{GW}_{\mathrm{M}}^{\mathrm{L}}$ & 64.9 & 51.5 & 71.6 & 12.75 \\
\hline $\mathrm{GW}_{\mathrm{H}}^{\mathrm{M}}$ & 62.3 & 53.1 & 69.4 & 12.50 \\
\hline $\mathrm{WW}^{\mathrm{H}}$ & $67.9^{\mathrm{a}}$ & 55.8 & $74.7^{\mathrm{a}}$ & $13.83^{\mathrm{a}}$ \\
\hline $\mathrm{WW}_{\mathrm{M}}^{\mathrm{L}}$ & 66.2 & 53.9 & 72.3 & 13.03 \\
\hline $\mathrm{WW}_{\mathrm{H}}^{\mathrm{M}}$ & 65.3 & 50.4 & 71.7 & 12.91 \\
\hline pooled SEM & 0.746 & 1.341 & 0.637 & 0.133 \\
\hline \multicolumn{5}{|l|}{$P$ - values } \\
\hline groups & 0.003 & 0.096 & 0.003 & $<0.001$ \\
\hline GW linear contrast & 0.599 & 0.140 & 0.542 & 0.445 \\
\hline GW quadratic contrast & $<0.001$ & 0.019 & $<0.001$ & $<0.001$ \\
\hline WW linear contrast & 0.225 & 0.378 & 0.349 & 0.405 \\
\hline WW quadratic contrast & 0.058 & 0.072 & 0.052 & 0.010 \\
\hline GW vs WW & 0.745 & 0.636 & 0.769 & 0.557 \\
\hline
\end{tabular}

${ }^{1}$ energy metabolizability = (gross energy - energy of the excreta): gross energy, \%; GW - diets with ground and pelleted wheat; $\mathrm{WW}$ - diets with whole wheat; $\mathrm{W}_{\mathrm{L}}, \mathrm{W}_{\mathrm{M}}$ and $\mathrm{W}_{\mathrm{H}}$ - low, medium and high wheat content, respectively; ${ }^{\mathrm{a} b \mathrm{~b}}$ the post-hoc two-sided Dunnett's test was used to determine differences between the control and each of the experimental groups. Means with different superscripts within the same column differ significantly $(\mathrm{P}<0.05)$

and the metabolizable energy content of the daily ration (C vs GW, quadratic contrast, $\mathrm{P}<0.001$; C vs WW, quadratic contrast, $\mathrm{P}=0.010$ ).

After four weeks of feeding, the experimental factors were found to exert different effects on the dry matter content of excreta and FPD occurrence (Table 4). The differences in the excreta dry matter content among groups were minor, but certain trends were observed relative to the control group: the decrease in the dry matter content of excreta was a linear trend in groups $\mathrm{GW}(\mathrm{P}=0.098)$ and quadratic in groups WW $(\mathrm{P}=0.002)$. The lowest dry matter content of excreta was noted in group $\mathrm{WW}_{\mathrm{L}}$, and a considerably higher value was observed in group $\mathrm{WW}_{\mathrm{H}}$. Wheat particle size did not significantly influence excreta dry matter content. In 8 -week-old turkeys, the symptoms of FPD were significantly less severe in groups $\mathrm{GW}_{\mathrm{L}}$ and $\mathrm{WW}_{\mathrm{L}}(\mathrm{P}=0.039)$. In the remaining groups, the effect of wheat inclusion was statistically non-significant. In birds aged 18 weeks, no significant differences were found among groups with respect to the dry matter content of excreta and FPD incidence, regardless of the experimental factors.

Neither the amount of wheat nor its physical form had a significant effect on the average body weight of growing turkeys (Table 5). Statistical analysis of the body weights of turkeys aged 8 and 12 weeks showed, however, that in the GW groups, body weight increased in response to low levels of ground wheat and decreased in response to high wheat inclusion, relative to the control group. 
Table 4. Dry matter (DM) content of the excreta and incidence of foot-pad dermatitis (FPD) in turkeys aged 8 and 18 week

\begin{tabular}{lccccc}
\hline \multirow{2}{*}{ Indices } & \multicolumn{2}{c}{8 week } & & \multicolumn{2}{c}{18 week } \\
\cline { 2 - 3 } \cline { 5 - 6 } & DM & FPD & & DM & FPD \\
\hline Groups & 20.1 & $2.84^{\mathrm{a}}$ & & 19.9 & 2.67 \\
C & 19.2 & $2.26^{\mathrm{b}}$ & & 20.2 & 2.68 \\
GW $_{\mathrm{L}}$ & 18.8 & 2.31 & & 20.3 & 2.49 \\
$\mathrm{GW}_{\mathrm{M}}$ & 18.9 & 2.34 & & 20.0 & 2.53 \\
$\mathrm{GW}_{\mathrm{H}}$ & 18.6 & $2.07^{\mathrm{b}}$ & & 19.7 & 2.50 \\
WW $_{\mathrm{L}}$ & 19.3 & 2.33 & & 20.1 & 2.56 \\
WW $_{\mathrm{M}}$ & 20.5 & 2.38 & & 19.4 & 2.73 \\
WW $_{\text {H }}$ & 0.196 & 0.062 & & 0.202 & 0.034 \\
pooled SEM & & & & & \\
P - values & 0.068 & 0.039 & & 0.932 & 0.367 \\
groups $_{\text {GW linear contrast }}$ & 0.098 & 0.033 & & 0.888 & 0.202 \\
GW quadratic contrast & 0.339 & 0.041 & & 0.638 & 0.890 \\
WW linear contrast & 0.263 & 0.105 & & 0.666 & 0.544 \\
WW quadratic contrast & 0.002 & 0.010 & & 0.660 & 0.077 \\
GW vs WW & 0.229 & 0.711 & & 0.354 & 0.727 \\
\hline
\end{tabular}

a-b the post-hoc two-sided Dunnett's test was used to determine differences between the control and each of the experimental groups. Means with different superscripts within the same column differ significantly $(\mathrm{P}<0.05)$; GW - diets with ground and pelleted wheat, WW - diets with whole wheat, $\mathrm{W}_{\mathrm{L}}, \mathrm{W}_{\mathrm{M}}$ and $\mathrm{W}_{\mathrm{H}}$ - low, medium and high wheat content, respectively

A similar trend was found for 12-week-old birds from groups WW, whose body weight increased in response to low and medium levels of whole wheat, and decreased in response to high wheat inclusion. In the first and second stages of the experiment (weeks 5-8 and 9-12), there were no significant differences in feed conversion ratio (FCR) among groups. In the third stage, FCR was significantly lower in groups $\mathrm{GW}_{\mathrm{H}}, \mathrm{WW}_{\mathrm{M}}$, and $\mathrm{WW}_{\mathrm{H}}$ than in the control group. FCR decreased linearly as the inclusion levels of ground or whole wheat in basal diets increased ( $\mathrm{P}=0.003$ in both cases), but throughout the experiment, only in groups $\mathrm{WW}_{\mathrm{M}}$ and $\mathrm{WW}_{\mathrm{H}}$ were FCR values lower that in group $\mathrm{C}(\mathrm{P}<0.001)$. The average FCR values between week 5-18 were significantly $(\mathrm{P}=0.004)$ lower in groups $\mathrm{WW}$ than in GW.

In birds aged 18 weeks, the yields of breast muscles, leg muscles (thigh and drumstick), and abdominal fat were similar in all groups (Table 6). Significant $(\mathrm{P}=0.026)$ differences were noted for gizzard weight, which was lower in the GW groups and higher in the WW groups $(\mathrm{P}=0.003)$. Turkeys fed diets with a high wheat content had a lower liver weight $(\mathrm{P}=0.013)$ in comparison with those fed diets with a low wheat content. 


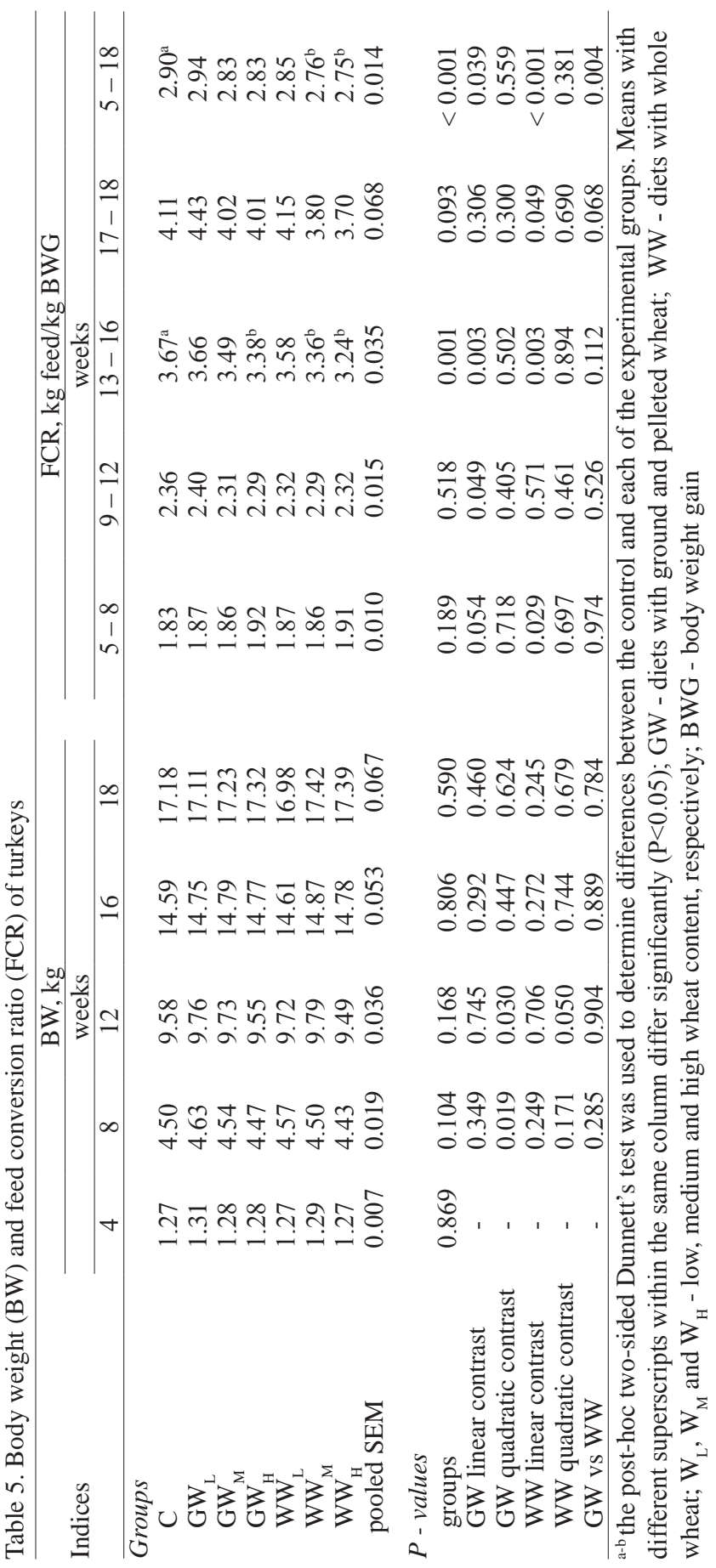


Table 6. Effect of dietary treatments on meat yield and abdominal fat content in turkeys, \% of live body weight

\begin{tabular}{|c|c|c|c|c|c|c|c|}
\hline \multirow{2}{*}{ Indices } & \multicolumn{3}{|c|}{ Muscles } & \multirow{2}{*}{$\begin{array}{c}\text { Abdominal } \\
\text { fat }\end{array}$} & \multicolumn{3}{|c|}{ Edible giblets } \\
\hline & breast & thigh & drumstick & & gizzard & liver & heart \\
\hline \multicolumn{8}{|l|}{ Groups } \\
\hline $\mathrm{C}$ & 22.9 & 11.3 & 7.97 & 1.12 & 0.63 & 1.06 & 0.34 \\
\hline $\mathrm{GW}_{\mathrm{I}}$ & 22.6 & 11.7 & 8.05 & 1.32 & 0.58 & 1.12 & 0.36 \\
\hline $\mathrm{GW}_{H}^{\mathrm{L}}$ & 24.2 & 10.9 & 7.72 & 1.20 & 0.56 & 0.96 & 0.36 \\
\hline $\mathrm{WW}_{\mathrm{T}}^{\mathrm{H}}$ & 23.0 & 10.9 & 7.73 & 1.29 & 0.65 & 1.13 & 0.37 \\
\hline $\mathrm{WW}_{\mathrm{H}}^{\mathrm{L}}$ & 23.5 & 11.1 & 8.11 & 1.23 & 0.72 & 1.05 & 0.35 \\
\hline SEM & 0.281 & 0.136 & 0.087 & 0.080 & 0.018 & 0.022 & 0.006 \\
\hline \multicolumn{8}{|l|}{$P$-values } \\
\hline groups & 0.438 & 0.456 & 0.864 & 0.771 & 0.026 & 0.086 & 0.270 \\
\hline GW vs WW & 0.825 & 0.448 & 0.853 & 0.988 & 0.003 & 0.280 & 0.882 \\
\hline $\mathrm{W}, \mathrm{vs} \mathrm{W}_{\mathrm{H}}$ & 0.108 & 0.379 & 0.906 & 0.636 & 0.487 & 0.013 & 0.510 \\
\hline
\end{tabular}

GW - diets with ground and pelleted wheat; $\mathrm{WW}$ - diets with whole wheat; $\mathrm{W}_{\mathrm{L}}, \mathrm{W}_{\mathrm{M}}$ and $\mathrm{W}_{\mathrm{H}}$ - low, medium and high wheat content, respectively

\section{DISCUSSION}

In our study, the dietary inclusion levels of wheat grain were relatively low, averaging $8.2 \%, 13.2 \%$, and $18.2 \%$. Thus, in diets with low, medium, and high wheat contents, the average protein concentration decreased by $3.4 \%, 5.8 \%$, and $8 \%$, respectively, in comparison with the control diet. The experimental diets met the protein requirements of growing turkeys (NRC, 1994).

In the first stage of the experiment, low $(5 \%)$ inclusion of wheat in the diets had a beneficial influence on dry matter digestibility, and on nitrogen and energy utilization. Irrespective of the level of wheat inclusion, wheat particle size had no significant effect on nutrient digestibility and utilization. Different results were reported for broiler chickens fed diets containing 10\%-20\% whole wheat, where metabolizable energy concentrations and amino acid digestibility were found to increase (Biggs and Parson, 2009). A positive effect of feeding whole cereals to broilers on the digestibility of nutrients, including starch, has also been observed by other authors (Hetland et al., 2002; Wu et al., 2004; Svihus et al., 2010), and could result from improved gastrointestinal motility (Amerah et al., 2007).

Compared with this study, relatively lower or similar results of body weight values were observed when turkeys were fed diets with soyabean protein products (Jankowski et al., 2009) and rapeseed meal (Mikulski et al., 2012). Diet dilution with wheat had no significant effect on the final body weight of turkeys. Despite certain differences in the growth rate of birds observed during the experiment, their final body weights were similar, regardless of the inclusion levels and physical form of wheat. In a study by Bennett et al. (2002b), total weight gain was also 
unaffected by feeding diets with $20 \%$ barley to turkeys with final body weights of $11 \mathrm{~kg}$. In another experiment by the same authors (Bennett and Classen, 2003), dilution of turkey diets with wheat (at 21\%-29\% on average) for 3 to 16 weeks markedly decreased final body weight and feed utilization. The results of our study and the findings of other authors indicate that the levels of diet dilution with wheat should be lower in turkeys than in broiler chickens, since in the latter even high inclusion levels of wheat (up to $30 \%$ ) do not decrease the final body weight.

In the current study, diet dilution with whole wheat vs ground and pelleted wheat, was found to improve FCR over the entire experimental period. These results differ from those reported by Bennett and Classen (2003) who found that dilution of turkey diets with whole wheat (21\%) caused a progressive decline in feed utilization in comparison with undiluted diets. The results of previous experiments on broiler chickens are also inconclusive: in some of them diet dilution with wheat improved FCR (Bennett et al., 2002a; Ravindran et al., 2006), while in others such an effect was not observed (Svihus et al., 2004; Amerah and Ravindran, 2008).

In our study, FPD incidence varied among young turkeys, but at the end of fattening (at the highest level of diet dilution with wheat) there were no significant differences among groups in this respect. Similarly, diet dilution with wheat had no significant effect on the dry matter content of excreta, and high excreta moisture is correlated with FPD occurrence in poultry (Wang et al., 1998).

Neither level nor form of wheat affected the proportions of major muscle groups (including breast muscles) in turkey carcasses. The experimental factors had no effect on the final body weights of birds, either. This suggests that the addition of wheat to diets, which reduced their total protein content, was well tolerated by growing turkeys. In a different experiment (Bennett and Classen, 2003), a high level of diet dilution with whole wheat (from $21 \%$ to $29 \%$ ) significantly reduced the final body weight and the weight of breast meat per bird, by $15 \%$ and $20 \%$, respectively. We did not note a decrease in carcass fatness in response to feeding wheat-diluted diets, which was reported in an experiment involving broiler chickens (Amerah and Ravindran, 2008).

\section{CONCLUSIONS}

The results of our study indicate that moderate (below 20\%, on average) dilution of standard turkey diets with wheat has no effect on the final body weights of birds or muscle yield, and improves feed utilization, in particular when whole wheat is fed instead of ground or pelleted grain. 


\section{REFERENCES}

Amerah A.M., Ravindran V., 2008. Influence of method of whole-wheat feeding on the performance, digestive tract development and carcass traits of broiler chickens. Anim. Feed Sci. Tech. 147, 326-339

Amerah A.M., Ravindran V., Lentle R.G., Thomas D.G., 2007. Influence of feed particle size on the performance, energy utilization, digestive tract development, and digesta parameters of broiler starters fed wheat- and corn-based diets. Poultry Sci. 72, 1731-1739

AOAC, 2005. Association of Official Analytical Chemists, Official Methods of Analysis. $18^{\text {th }}$ Edition. Arlington, VA

Aviagen Inc., 2007. Management Essentials for Commercial Turkeys (available at http://en. aviagen. $\mathrm{com} /$ )

Bennett C.D., Classen H.L., 2003. Influence of whole wheat dilution on performance and carcass characteristics of male turkey. J. Appl. Poultry Res. 12, 468-475

Bennett C.D., Classen H.L., Riddell C., 2002a. Feeding broiler chickens wheat and barley diets containing whole, ground and pelleted grain. Poultry Sci. 81, 995-1003

Bennett C.D., Classen H.L., Schwean K., Riddell C., 2002b. Influence of whole barley and grit on live performance and health of turkey toms. Poultry Sci. 81, 1850-1855

Biggs P., Parsons C.M., 2009. The effect of whole grains on nutrient digestibilities, growth performance, and cecal short-chain fatty acid concentrations in young chicks fed ground cornsoybean meal diets. Poultry Sci. 88, 1893-1905

BUT, 2005. Commercial Performance Goals. British United Turkeys Ltd. $5^{\text {th }}$ Edition. Warren Hall, Broughton, Chester (UK) (available at http://www.aviagen.com/home.aspx?siteId=8)

Gabriel I., Mallet S., Leconte M., Travel A., Lalles J.P., 2008. Effect of whole wheat feeding on the digestive tract of broiler chickens. Anim. Feed Sci. Tech. 142, 144-162

Hetland H., Svihus B., Olaisen V., 2002. Effect of feeding whole cereals on performance, starch digestibility and duodenal particle size distribution in broiler chickens. Brit. Poultry Sci. 43, 416-423

Hocking P.M., Mayne R.K., Else R.W., French N.A., Gatcliffe J., 2008. Standard European system for use in turkey processing plants. World Poultry Sci. J. 64, 323-328

Jankowski J., Juskiewicz J., Gulewicz K., Lecewicz A., Slominski B.A., Zdunczyk Z., 2009. The effect of diets containing soybean meal, soybean protein concentrate, and soybean protein isolate of different oligosaccharide content on growth performance and gut function of young turkeys. Poultry Sci. 88, 2132-2140

Majewska T., 1996. Whole wheat grain in turkeys feeding (in Polish). Acta Acad. Agric. Tech. Olszt. 43, Suppl. 43, 1-64

Mikulski D., Jankowski J., Zdunczyk Z., Juskiewicz J., Slominski B.A., 2012. The effect of different dietary levels of rapeseed meal on growth performance, carcass traits, and meat quality in turkeys. Poultry Sci. 91, 215-223

NRC, 1994. Nutrient Requirements of Poultry. $9^{\text {th }}$ revised Edition. National Academic Press. Washington, DC

Ravindran V., Wu Y.B., Thomas D.G., Morel P.C.H., 2006. Influence of whole wheat feeding on the development of gastrointestinal tract and performance of broiler chickens. Aust. J. Agr. Res. $57,21-26$

StatSoft Inc., 2007. Statistica (data analysis software system), Version 8.0. Accessed Jan. 16, 2011. http://www.statsoft.com

Svihus B., 2011. The gizzard: function, influence of diet structure and effects on nutrient availability. World Poultry Sci. J. 67, 207-223 
Svihus B., Juvik E., Hetland H., Krogdahl A., 2004. Causes for improvement in nutritive value of broiler chicken diets with whole wheat instead of ground wheat. Brit. Poultry Sci. 45, 55-60

Svihus B., Sacranie A., Denstadli V., Choct M., 2010. Nutrient utilization and functionality of the anterior digestive tract caused by intermittent feeding and inclusion of whole wheat in diets for broiler chickens. Poultry Sci. 89, 2617-2625

Wang G., Ekstrand C., Svedberg J., 1998. Wet litter and perches as risk factors for the development of foot-pad dermatitis in floor hens. Brit. Poultry Sci. 39, 191-197

Wu Y.B., Ravindran V., 2004. Influence of whole wheat inclusion and xylanase supplementation on the performance, digestive tract measurements and carcass characteristics of broiler chickens. Anim. Feed Sci. Tech. 116, 129-139

Wu Y.B., Ravindran V., Thomas D.G., Birtles M.J., Hendriks W.H., 2004. Influence of method of whole wheat inclusion and xylanase supplementation on the performance, apparent metabolizable energy, digestive tract measurements, and gut morphology of broilers. Brit. Poultry Sci. 45, 385-394 